\title{
Application of the BPCQ questionnaire to assess pain management in selected types of cancer
}

\author{
Aleksandra Czerw' ${ }^{1}$, Urszula Religioni ${ }^{1}$, Andrzej Deptała ${ }^{2}$, Adam Fronczak ${ }^{1}$ \\ 1 Public Health Department, Medical University of Warsaw, Poland \\ ${ }^{2}$ Division of Cancer Prevention, Medical University of Warsaw and Department of Oncology and Hematology \\ CSK MSWiA, Poland
}

Czerw A, Religioni U, Deptała A, Fronczak A. Application of the BPCQ questionnaire to assess pain management in selected types of cancer. Ann Agric Environ Med. 2016; 23(4): 533-538. doi: 10.5604/12321966.1220212

\begin{abstract}
Introduction. Pain is one of the most prevalent unpleasant sensation in people that may significantly lower the quality of life. More than a half of cancer patients suffer from various forms of pain, which becomes more frequent and intense as disease progresses.

Objective. The objective of the study was to assess the degree of pain control in patients diagnosed with breast, lung, colorectal and prostate cancer. The analysis also covered the effect of socio-economic factors on pain management in patients with the above types of cancer.

Materials and method. The study included 902 patients treated at the Outpatient's Department of the Maria SklodowskaCurie Memorial Cancer Center - Institute of Oncology in Warsaw in 2013. The patients consisted of those diagnosed with breast, lung, colorectal or prostate carcinoma. The Paper and Pencil Interview (PAPI) technique was applied. A questionnaire interview included demographic-type questions (socio-economic variables) and the Beliefs about Pain Control Questionnaire (BPCQ) test which measures the power of factors influencing pain control in patients.

Results. It was demonstrated that regarding beliefs in the source of pain control, patients attributed the highest importance to the power of doctors (mean value $=16.60$ ) and the lowest to chance events (mean $=15.82$ ). The internal factors are regarded as having the strongest influence by respondents diagnosed with colorectal or breast cancer. With regards to the locus of pain control, only the internal control of pain is diversified by the primary site.

Conclusions. With regards to the source of pain management, only the internal control of pain is diversified by the primary site. The external factors were regarded as having the strongest influence by respondents diagnosed with colorectal or breast cancer. The major socio-economic variables differentiating the way in which pain control is perceived are education and net income-per-household-member. The results of analyses of individual groups of patients revealled strong correlations between the beliefs in the doctors' influence, and the beliefs in chance events and socio-economic factors.
\end{abstract}

\section{Key words}

$B P C Q$, pain, pain management, cancer, quality of life

\section{INTRODUCTION}

After cardiovascular diseases, cancer is the second most common cause of death in developed countries [1]. According to estimates made by epidemiologists, the incidence and death rate of cancer worldwide will probably grow in the coming decades, in particular among patients over 65 years of age [2]. In the light of research, pain management significantly impacts the treatment of many chronic diseases, including cancer [3]. An active approach to diseases may result in better therapeutic effects for numerous diseases, especially cancer [4]. Studies have been conducted indicating the impact of socio-economic variables on problems associated with pain management $[5,6]$. Variables, such as gender, age, education and the socio-economic status, differentiate patients in terms of the aspects specified above. It is not uncommon that younger patients with higher education and high socioeconomic status apply more effective strategies for pain management.

Pain is amongst the most frequent sensations affecting human beings and causing discomfort and a marked

Address for correspondence: Aleksandra Czerw, Medical University of Warsaw Department of Public Health, 1a Banacha, 02-097 Warsaw, Poland

E-mail: aleksandra.czerw@wum.edu.pl

Received: 12 November 2015; accepted: 25 August 2016 reduction in life quality. According to the definition of the IASP (International Association for the Study of Pain), pain is 'an unpleasant sensory and emotional experience associated with actual or potential tissue damage, or described in terms of such damage' [3].

Based on the above definition, two characteristic components of pain can be distinguished, i.e. a sensory experience, associated with the perception of pain, and an emotional experience, related to an individual reaction of a patient in response to pain stimulus. It needs to be noted that the emotional experience component of pain is subjective, which explains why the feeling of pain varies across different patients.

Pain is thought to be present always when the patient reports it. Pain is referred to as chronic pain when it lasts for more than 3 months [7]. Nevertheless, a detailed assessment of the incidence of cancer pain and its intensity is extremely difficult. National registers of cancers cover numerous different data regarding diseases, such as disease incidence rates, mortality rates or types of cancer. However, the professional literature lacks detailed information regarding the types of pain present in cancer patients [8].

Considering the problem of pain management and the impact of socio-economic variables on the above concept, it seems reasonable to conduct further research in the field. 
Such research would constitute an important element in the education of psychologists, physicians and patients, and help to improve factors which contribute to a decrease in pain and increase in the quality of life.

Based on the available studies about the impact of pain management on the achieved therapeutic effects in patients with chronic diseases $[6,9,10]$, the authors assumed hypotheses regarding the impact of pain management on the treatment of patients with prostate, lung, colorectal and breast cancer. The identified groups of patients were selected through epidemiological data. The identified cancers are those most frequently occurring in Poland, and simultaneously, they cause the highest number of deaths resulting from cancer. In Poland in 2013, the most frequently occurring cancers in men were cancer of the lung (21\%), prostate (13\%) and colon (12\%). Among women, the most frequent cancers were those of the breast (22\%), colon (10\%) and lung (9\%). Men died most frequently due to lung cancer (31\% of deaths among deaths resulting from cancer), colon cancer $(12 \%$ of deaths) and prostate cancer $(8 \%)$. Women died most frequently due to lung cancer (15\%), breast cancer (13\%) and colon cancer (12\%) [1].

There have also been some hypotheses formulated concerning the effect of socio-economic variables, including professional status, place of residence, income and education, on the fields specified above in the selected groups of patients.

\section{OBJECTIVE}

The major research objective was to determine a correlation between the primary site and the degree of pain control. The analysis also included dependencies between socio-economic factors and pain management in breast, lung, colorectal and prostate cancer patients.

\section{MATERIALS AND METHOD}

The study included 902 patients treated at the Outpatients' Department of the Maria Sklodowska-Curie Memorial Cancer Center - Institute of Oncology in Warsaw in 2013. The patients consisted of those diagnosed with breast, lung, colorectal or prostate carcinoma.

The study investigated only those patients with cancer disease who did not experience any other conditions/ comorbidities that might have caused pain, based on the opinion of the attending oncologist. The study group was selected based on the incidence of cancer among the Poles. Carcinoma types which are significant in terms of epidemiology were selected. The Paper and Pencil Interview (PAPI) technique was applied. A questionnaire interview included demographic-type questions (socio-economic variables) and the Beliefs about Pain Control Questionnaire (BPCQ) test which measures the power of factors influencing pain control in patients.

The BPCQ developed by S. Skevington is designed for use with patients suffering from pain [11]. It consists of 13 statements which form 3 subscales that measure the power of individual beliefs regarding pain management: internally (internal factors), through doctors (powerful others), and chance events. Each of the statements is evaluated by the respondent on a scale from $1-6$, where 1 signifies 'No, I completely disagree', and 6 - 'Yes, I completely agree'. The total score for every BPCQ subscale is calculated separately on the basis of the sum of points awarded to each statement. The higher the score, the stronger the impact of a given subscale on pain management in a particular patient.

Cronbach's Alpha co-factors were employed in the analysis of BPCQ scale reliability. The coefficient for the whole test was 0.81 , which is higher than the standardization process coefficient, where reliability in a 138-patient sample was 0.75 [4]. Furthermore, separate reliability analyses for each of the subscales were conducted (Tab. 1).

Table 1. Analysis of reliability of the BPCQ subscales

\begin{tabular}{lcc}
\hline BPCQ subscale & Cronbach's Alpha & $\begin{array}{c}\text { Cronbach's Alpha in a } \\
\text { standardized study }\end{array}$ \\
\hline Internal factors & 0.81 & 0.82 \\
\hline Power of doctors & 0.85 & 0.86 \\
\hline Chance events & 0.68 & 0.58 \\
\hline
\end{tabular}

The resultant reliability appeared to be almost identical to that in the standardization study for internally controlled pain and doctors' power, and somewhat higher in the case of chance events.

All patients with cancer meeting the inclusion criteria participated in the study. The inclusion criteria were as follows: 1) 18 years or older, 2) a diagnosis of breast, prostate, lung, or colorectal cancer made since 2010,3) informed consent expressed in writing.

The selected study method allowed investigators to obtain a sample with the characteristics of a representative sample since it consisted of various categories of respondents and was based on their random visits at the Center. The sample included patients with diverse primary sites, different genders, places of residence, education levels and income.

One essential feature of the sample in this large quantitative study was its size. 902 respondents participated in the study; hence, reliable material for statistical comparisons was obtained, and risk of the effect of extreme cases on mean scores was minimized.

The Kruskal-Wallis and ANOVA were used for the purpose of statistical analysis of results variance between the study groups. The Mann-Whitney $U$ test was employed for the comparison of differences between the 2 study groups. The adopted statistical significance was at $\mathrm{p}<0.05$.

The study was conducted with the approval of the Bioethics Committee at the Medical University of Warsaw on 16 April 2013.

The patients were informed that the study was carried out by the Medical University of Warsaw and familiarized with the study purpose. Each study subject was informed that the results obtained would be used for research purposes only.

\section{RESULTS}

The sample structure classified by primary sites is shown in Table 2 .

Regarding the source of pain control, only internal control of pain of the 3 subscales of the BPCQ is diversified by the primary site. In order to prove said correlations, an analysis 
Table 2. Sample structure classified by primary site

\begin{tabular}{lc}
\hline Primary site & Sample \\
\hline Breast & 193 \\
\hline Lung & 243 \\
\hline Colon/rectum & 238 \\
\hline Prostate & 228 \\
\hline Total & 902 \\
\hline
\end{tabular}

of variance preceded by Levene's test was conducted for the chance events subscale. In the case of the remainder of subscales (internal factors and the power of doctors), a nonparametric Kruskal-Wallis analysis was performed. The internal factors are regarded as having the strongest influence on pain control by respondents diagnosed with colorectal cancer $($ mean value $=17.36$ ). At the same time, it was the only score exceeding the mean for the whole sample, which was 16.24. Breast cancer patients scored a little below the mean value (16.11). The lowest results were achieved by prostate cancer patients (15.82) and lung cancer patients (15.64) (Tab. 3).

Table 3. Internal factors vs. primary site

\begin{tabular}{lccc}
\hline BPCQ internal factors & Mean & Standard deviation & N \\
\hline Breast & 16.11 & 5.278 & 193 \\
\hline Lung & 15.64 & 6.193 & 243 \\
\hline Colon/rectum & 17.36 & 5.484 & 238 \\
\hline Prostate & 15.82 & 6.311 & 228 \\
\hline
\end{tabular}

The results of analyses of individual groups of patients demonstrated strong correlations between the beliefs in doctors' influence and the beliefs in chance events and socioeconomic factors. However, the correlation coefficients varied depending on the primary site.

The subscale involving the power of doctors and the influence of chance events were strongly correlated. Groups which scored the highest in one of the above subscales also scored the highest in the other. The major socioe-conomic variables differentiating the way in which pain control is perceived are education and net income-per-householdmember. Those with a higher education and income attribute less influence on pain management to both of the mentioned subscales, most likely due to additional sources of impact on their own pain, such as financial means and family support. A plausible explanation of the observed tendencies is the fact that well-educated people treat others with more reserve and have more balanced judgments, thus are less prone to be extreme in their views.

The effect of socioeconomic factors on pain management in breast cancer patients. In the case of breast cancer patients, statistically significant dependencies between education and professional status and the subscales of pain control were recorded. The attribution of influence to doctors clearly decreases along increase in education. In persons of vocational education, the mean result in this subscale of the scale is 17.81; in high-school graduates it is 17.33; whereas, in respondents educated at a higher level, it is a mere 16.04. Nevertheless, the rise in the level of education brings about the rise in group internal diversification. The tendency to attribute the power over pain control to chance events is also reduced along the increase in education. Still, the drop in this case is much more pronounced. Respondents of vocational education have a mean score of 18.81; those of high-school education - 16.63; while university graduates - only 14.73 . This subscale also involves a noticeable growth in results' diversification along the decrease in the mean value. Standard deviation in the case of patients with vocational education is 3.54; whereas, for high-school and university graduates it is only 4.01 and 4.35 , respectively (Tab. 4).

Table 4. BPCQ test results for patients with breast cancer in various education groups

\begin{tabular}{lllll}
\hline BPSQ subscale & Education & $\mathrm{N}$ & Mean & Standard deviation \\
\hline \multirow{4}{*}{ Internal factors } & Elementary & 13 & 18.00 & 6.338 \\
\cline { 2 - 5 } & Vocational & 21 & 18.19 & 5.510 \\
\cline { 2 - 5 } & High-school & 89 & 16.16 & 5.119 \\
\cline { 2 - 5 } & Higher & 70 & 15.09 & 5.027 \\
\cline { 2 - 5 } Power of doctors & Total & 193 & 16.11 & 5.278 \\
\cline { 2 - 5 } & Elementary & 13 & 20.00 & 3.215 \\
\cline { 2 - 5 } & Vocational & 21 & 17.81 & 4.070 \\
\cline { 2 - 5 } & High-school & 89 & 17.33 & 4.245 \\
\cline { 2 - 5 } & Total & 70 & 16.04 & 4.630 \\
\hline Chance events & Elementary & 13 & 18.00 & 4.403 \\
\hline \multirow{3}{*}{} & Vocational & 21 & 18.81 & 3.041 \\
\hline & High-school & 89 & 16.63 & 4.097 \\
\hline & Higher & 70 & 14.73 & 4.347 \\
\hline & Total & $\mathbf{1 9 3}$ & $\mathbf{1 6 . 2 7}$ & $\mathbf{4 . 3 1 8}$ \\
\hline & & & & \\
\hline & & & 17.09 & 4.403 \\
\hline
\end{tabular}

The belief in the power of doctors in pain management was further diversified by the professional status of the respondents. Both the pensioners and the homemakers attribute more power to influence their health condition to doctors than the employed patients do (Tab. 5).

Table 5. BPCQ test results for patients with breast cancer of various professional status

\begin{tabular}{llccc}
\hline BPSQ subscale & Professional status & $\mathrm{N}$ & Mean & Standard deviation \\
\hline \multirow{4}{*}{ Internal factors } & Employed & 92 & 15.93 & 5.316 \\
\cline { 2 - 5 } & Pensioner & 87 & 16.16 & 5.133 \\
\cline { 2 - 5 } & Homemaker & 10 & 17.40 & 5.441 \\
\cline { 2 - 5 } & Unemployed & 4 & 16.00 & 8.679 \\
\cline { 2 - 5 } & Total & 193 & 16.11 & 5.278 \\
\hline \multirow{5}{*}{ Power of doctors } & Employed & 92 & 16.40 & 4.373 \\
\cline { 2 - 5 } & Pensioner & 87 & 17.77 & 4.162 \\
\cline { 2 - 5 } & Homemaker & 10 & 18.10 & 5.953 \\
\cline { 2 - 5 } & Unemployed & 4 & 15.75 & 4.924 \\
\cline { 2 - 5 } & Total & 193 & 17.09 & 4.403 \\
\hline \multirow{5}{*}{ Chance events } & Employed & 92 & 16.28 & 4.323 \\
\cline { 2 - 5 } & Pensioner & 87 & 16.43 & 4.382 \\
\cline { 2 - 5 } & Homemaker & 10 & 15.80 & 3.706 \\
\cline { 2 - 5 } & Unemployed & 4 & 13.75 & 4.992 \\
\hline & Total & 193 & 16.27 & 4.318 \\
\hline & & &
\end{tabular}


The effect of socioeconomic factors on pain management in lung cancer patients. In patients diagnosed with lung cancer, the socioeconomic variables which differentiated pain management were education, professional status and net-income-per-household-member. Lung cancer respondents' education differentiates results obtained in the internal factors and chance events subscales. In the former subscale, considerable differences between the scores of people of vocational education (17.07), and those of highschool or higher education (14.21 and 15.14, respectively) could be noted. With regards to the letter subscale, respondents with vocational (16.41) and higher (16.16) level education scored consistently; whereas, the lowest scores were obtained by high-school graduates (15.15). Respondents who are retired ascribe more control over pain to chance events (mean value $=16.29$ ) than the professionally active do (15.03). As part of the net income-per-household-member variable in persons with lung as the primary site, a linear dependency for each individual subscale was demonstrated. Nevertheless, statistical significance was confirmed only for the chance events subscale $(\mathrm{p}=0.042)$ (Tab. 6). The mean values for the beliefs that pain is controlled by chance events subscale range from 17.46 in the lowest income respondents to 14.58 in the highest income patients. It indicates that an increase in income causes a decrease in the number of opinions that chance events control pain.

Table 6. BPCQ test results for lung cancer patients classified by net income-per-household-member

\begin{tabular}{|c|c|c|c|c|}
\hline BPSQ subscale & Income & $\mathrm{N}$ & Mean & Standard deviation \\
\hline \multirow{6}{*}{ Internal factors } & Less than PLN 300 & 5 & 19.80 & 2.490 \\
\hline & PLN 300-600 & 48 & 16.67 & 6.602 \\
\hline & PLN 601-900 & 78 & 16.00 & 6.674 \\
\hline & PLN 901-1200 & 67 & 15.45 & 5.112 \\
\hline & PLN 1201-1500 & 45 & 13.73 & 6.290 \\
\hline & Total & 243 & 15.64 & 6.193 \\
\hline \multirow{6}{*}{ Power of doctors } & Less than PLN 300 & 5 & 16.40 & 5.030 \\
\hline & PLN 300-600 & 48 & 18.17 & 6.322 \\
\hline & PLN 601-900 & 78 & 17.13 & 5.469 \\
\hline & PLN 901-1200 & 67 & 16.49 & 4.806 \\
\hline & PLN 1201-1500 & 45 & 15.24 & 5.540 \\
\hline & Total & 243 & 16.79 & 5.519 \\
\hline \multirow{6}{*}{ Chance events } & Less than PLN 300 & 5 & 16.20 & 5.805 \\
\hline & PLN 300-600 & 48 & 17.46 & 5.006 \\
\hline & PLN 601-900 & 78 & 16.32 & 4.992 \\
\hline & PLN 901-1,200 & 67 & 16.13 & 4.369 \\
\hline & PLN 1,201-1,500 & 45 & 14.58 & 5.070 \\
\hline & Total & 243 & 16.17 & 4.903 \\
\hline
\end{tabular}

Effect of socio-economic factors on pain management in colorectal cancer patients. The majority of differences in the location of pain control were determined in the colorectal carcinoma patient group. The variables differentiating the scores include: sex, education, net income-per-householdmember, and one's professional status. Across all subscales of the BPCQ males suffering from colorectal cancer scored slightly higher than females. However, only in the case of "powerful doctors" the differences proved statistically significant $(\mathrm{p}=0.027)$. The mean test score was 16.84 for men and 15.53 for women. The greatest impact of doctors on pain control was registered by elementary education patients, the lowest - by higher education patients (14.74). Vocational and high-school graduates achieved consistent mean results: 16.66 and 16.34 , respectively. With regards to the chance events subscale, the score mean was 16.89 in elementary education respondents, 16.91 in vocational education patients, slightly less, i.e. 15.80, in high-school education respondents, and merely 13.60 in those of higher education. The above cited outcomes in the study groups of various degrees of education proved statistically significant ( $p=0.016$ for doctors' power and $p=0.001$ for chance events). It indicates that respondent's education is inversely correlated with the influence of doctors and chance events on pain management. The means obtained in individual subscales of the questionnaire also decrease with an increase in respondents' income. Still, in the case of beliefs in internal control over pain no significant statistical difference was demonstrated $(\mathrm{p}=0.345)$. In the doctors' impact on pain management subscale the mean result ranges from 17.44 in patients with PLN 300 - 600 of net income-per-householdmember, 16.76 and 15.96 in respondents with an income of PLN $601-900$ and 901 - 1200, respectively, up to only 14.27 in the case of respondents with the highest income. In the subscale involving chance events having control over pain we can notice a clear difference between two groups with the lowest income, where mean scores obtained were 16.81 and 16.68 , respectively, and the remaining two groups, with mean scores 14.96 and 13.91. In the powerful doctors' subscale, the pensioners' mean score was 17.21, whereas that of the employed patients - only 14.94. Furthermore, the pensioners scored higher in the chance events subscale (mean value = 16.78) in comparison with employed respondents (14.06). However, the above difference demonstrated to be statistically significant $(\mathrm{p}=0.001$ for beliefs in doctors' power and $\mathrm{p}=0.000$ for chance events) (Tab. 7).

Table 7. BPCQ test results for patients with colorectal cancer grouped by professional status

\begin{tabular}{|c|c|c|c|c|}
\hline BPCQ subscale & Professional status & $\mathrm{N}$ & Mean & Standard deviation \\
\hline \multirow{6}{*}{ Internal factors } & Employed & 79 & 17.15 & 5.003 \\
\hline & Student & 2 & 25.00 & 7.071 \\
\hline & Pensioner & 140 & 17.81 & 5.599 \\
\hline & Homemaker & 13 & 13.85 & 4.723 \\
\hline & Unemployed & 4 & 13.00 & 6.164 \\
\hline & Total & 238 & 17.36 & 5.484 \\
\hline \multirow{6}{*}{ Power of doctors } & Employed & 79 & 14.94 & 4.550 \\
\hline & Student & 2 & 23.50 & .707 \\
\hline & Pensioner & 140 & 17.21 & 4.735 \\
\hline & Homemaker & 13 & 14.08 & 6.383 \\
\hline & Unemployed & 4 & 14.75 & 5.679 \\
\hline & Total & 238 & 16.30 & 4.928 \\
\hline \multirow{6}{*}{ Chance events } & Employed & 79 & 14.06 & 4.810 \\
\hline & Student & 2 & 19.50 & 6.364 \\
\hline & Pensioner & 140 & 16.78 & 4.233 \\
\hline & Homemaker & 13 & 14.54 & 5.317 \\
\hline & Unemployed & 4 & 13.25 & 5.123 \\
\hline & Total & 238 & 15.72 & 4.682 \\
\hline
\end{tabular}


Effect of socio-economic factors on pain management in prostate cancer patients. Amongst respondents with prostate as the primary site, BPCQ test result differentiation by socioeconomic variables is rare. Beliefs that pain is managed by chance events is differentiated by respondents' net incomeper-household-member $(\mathrm{p}=0.008)$, while beliefs in chance events and doctors' control is differentiated by one's professional status ( $\mathrm{p}=0.035$ and $\mathrm{p}=0.025$, respectively). In the chance events subscale, definitely the highest mean scores were achieved by respondents with an income of PLN 601 - 900 (16.96). The poorest results were obtained by patients with an income of PLN $300-600$ (15.48). The top income groups had the lowest scores: the PLN 901 - 1200 income patients (14.32) and the PLN 1201 - 1500 income respondents (14.15). Pensioners score highest in ascribing control over pain to doctors and chance events: 16.79 at 14.94 for doctors' power and 15.54 at 13.81 for chance events (Tab. 8).

Table 8. BPCQ test results for patients with prostate cancer grouped by professional status

\begin{tabular}{llccc}
\hline BPCQ subscale & Professional status & $\mathrm{N}$ & Mean & Standard deviation \\
\hline \multirow{4}{*}{ Internal factors } & Employed & 62 & 15.40 & 5.982 \\
\cline { 2 - 5 } & Pensioner & 156 & 15.96 & 6.469 \\
\cline { 2 - 5 } & Homemaker & 3 & 17.33 & 5.859 \\
\cline { 2 - 5 } & Unemployed & 7 & 15.71 & 6.873 \\
\cline { 2 - 5 } & Total & 228 & 15.82 & 6.311 \\
\hline \multirow{5}{*}{ Power of doctors } & Employed & 62 & 14.94 & 5.188 \\
\cline { 2 - 5 } & Pensioner & 156 & 16.79 & 5.077 \\
\cline { 2 - 5 } & Homemaker & 3 & 17.67 & 2.887 \\
\cline { 2 - 5 } & Unemployed & 7 & 17.29 & 5.469 \\
\cline { 2 - 5 } & Total & 228 & 16.31 & 5.141 \\
\hline \multirow{3}{*}{ Chance events } & Employed & 62 & 13.81 & 5.166 \\
\cline { 2 - 5 } & Pensioner & 156 & 15.54 & 4.984 \\
\cline { 2 - 5 } & Homemaker & 3 & 17.67 & 1.528 \\
\cline { 2 - 5 } & Unemployed & 7 & 18.00 & 4.397 \\
\hline & Total & 228 & 15.17 & 5.059 \\
\hline & & & \\
\hline
\end{tabular}

\section{DISCUSSION}

It is estimated that pain in cancer is sensed by more than a half of all patients [12], and by $80-90 \%$ of patients in the end stage disease [13]. However, cancer and pain related to it is not limited to patients themselves as it extends to patient families. In view of the above, pain control not only may increase the quality of life of said patients but also that of their families and friends by soothing the sense of hopelessness when faced with illness.

Numerous guidelines regarding pain management in cancer have been developed to date $[14,15]$. The most popular ones are the recommendations of the World Health Organization [16], which denote that the selection of medications should account for an individual patient condition and current pain intensity.

Yet, pain is a subjective feeling and as a consequence there are many problems with regards to choosing the right therapy. Patients with a corresponding primary site may differ in terms of pain intensity and in the way they react to painkillers [17]. In addition to the common practice of describing pain experience (e.g. as a mild or strong pain), other, more objective scales are available. One of them is the Visual Analogue Scale (VAS) that allows one to describe pain on a numerical scale (from 0 to 10 , where 0 means no pain and 10 - the strongest pain) [14].

Because cancer pain is multivariate, various medicinal products, different dosing or methods of administration are used in pain therapy, depending on disease type and stage. It is recommended that cancer pain assessment involves its intensity, time, characteristic features and location. Furthermore, it is advised that doctors pay special attention to psychological aspects of pain in their patients, such as fear or anxiety, which may have a significant impact on the way they perceive and experience pain [5]. The analysis of periodic pain management should become a tool used to improve quality of pain treatment in patients.

Additionally, we should focus our attention on the meaning of psychological factors, such as directing one's attention to the experience of pain, patients' attitude towards pain and illness, expectation (e.g. as to the term of treatment) $[18,19]$, the ability to cope with emotions, or of reaction to pain [20, 21], in the intensity of pain sensation.

Studies prove that the sense of control over pain can improve functioning and quality of life of patients suffering from cancer [11, 4, 3 and others]. It seems that formation and development of the inner control locus in the case of patients experiencing pain are absolutely essential. In order to achieve this, behavior-cognitive techniques can be applied as they focus on supporting stress management methods as well as pain. There are various forms of professional social support available for people suffering from chronic pain. Medical care, including physiotherapy, is the most fundamental form of support. Working with a therapist is important. Such individual work can have a traditional form concerning areas such as: work with imagination (focusing on nice images), work on belief regarding the ability to control pain, work on beliefs causing negative emotions (e.g. I will suffer forever). Education and knowledge in areas essential for pain management should also be remembered. These areas include: knowledge of diet and nutrition, ability to decease pain, basic knowledge of care (e.g. to prevent painful bedsores) or practicing how to handle painkillers, e.g. principles how to administer opioids. Finally, it is also important to remember about material support in the form of acquisition of certain medicine or medical equipment (e.g. deeding pumps or inhalers) as well as rehabilitation equipment (e.g. walkers or wheelchairs) which help in pain management.

\section{CONCLUSIONS}

1. With regards to the source of pain control, only internal control of pain is diversified by the primary site.

2. Internal factors are regarded as having the strongest influence by respondents diagnosed with colorectal or breast cancer.

3. The results of analyses of individual groups of patients reveal strong correlations between the beliefs in doctors' influence and chance events and socioeconomic variables.

4. The main variables diversifying the beliefs about pain management is education and net income-per-householdmember. 


\section{REFERENCES}

1. Krajowy Rejestr Nowotworów, http://onkologia.org.pl/ (access: 12.03.2016)

2. World Cancer Report 2008, http://www.iarc.fr/en/publications/pdfsonline/wcr/2008/wcr_2008.pdf (access: 12.03.2016).

3. International Association for the Study of Pain, IASP Taxonomyhttp:// www.iasp-pain.org/Education/Content.aspx?ItemNumber=1698\&nav ItemNumber $=576 \#$ Pain (term: pain) (access: 20.07.2016).

4. Juczyński J. Measurement tools in health promotion and psychology, Pracownia testów psychologicznych, Warszawa 2009: 165 (in Polish).

5. Turk DC, Monarch ES, Williams AD. Review Cancer patients in pain: considerations for assessing the whole person. Hematol Oncol Clin North Am. 2002 Jun; 16(3): 511-525.

6. Misterska E, Jankowski R, Głowacki M. Chronic pain coping styles in patients with herniated lumbar discs and coexisting spondylotic changes treated surgically: Considering clinical pain characteristics, degenerative changes, disability, mood disturbances, and beliefs about pain control. Med Sci Monit. 2013; 19: 1211-1220.

7. Tennant F, Hermann L. Intractable or chronic pain. West J Med. 2000; 173(5): 306.

8. Hilgier M, Jarosz J. Leczenie bólu u chorych na nowotwór - standardy i wytyczne. Terapia 2006; 11(86): 35-41.

9. Asqari A, Nicholas M. Pain self-efficacy beliefs and pain behavior. A prospective study. Pain 2001; 94(1): 85-100.

10. Turk DC, Monarch ES, Williams AD. Review Cancer patients in pain: considerations for assessing the whole person. Hematol Oncol Clin North Am. 2002 Jun; 16(3): 511-525.
11. Skevington SM. A standardised scale to measure beliefs about controlling pain (BPCQ): a preliminary study. Psychol Health. 1990; 4: $221-232$

12. Nersesyan H, Slavin KV. Current approach to cancer pain management: Availability and implications of different treatment options. Ther Clin Risk Manag. 2000; 3(3): 381.

13. Pharo GH, Zhou L. Review Pharmacologic management of cancer pain. J Am Osteopath Assoc. 2005; 105(11 Suppl 5): 21-28.

14. NCCN Practice Guidelines for Cancer Pain. Benedetti C, Brock C, Cleeland et al. National Comprehensive Cancer Network Oncology (Williston Park) 2000; 14(11A): 135-50.

15. Panchal SJ, Anghelescu DL, Benedetti C, et al. Adult cancer pain. Clinical Practice Guidelines in Oncology (version 2.2005), ccess: 20.12.2014).

16. World Health Organization. Cancer pain relief - with a guide to opioid availability $-2^{\text {nd }}$ ed, Geneva 1996.

17. Noble B, Clark D, Meldrum M, et al. The measurement of pain. J Pain Symptom Manage 2005 Jan; 29(1): 14-21.

18. Petrie KJ, Jago LA, Devcich DA. The role of illness perceptions in patients with medical conditions. Curr Opin Psychiatry. 2007; 20:163167.

19. Czerw A, Religioni U, Deptała A. Assessment of pain, acceptance of illness, adjustment to life with cancer and coping strategies in breast cancer patients, Breast Cancer, DOI: $10.1007 /$ s12282-015-0620-0.

20. Linton SJ, Shaw WS. Impact of psychological factors in the experience of pain. Phys Ther. 2011; 91(5): 700-711.

21. Czerw A, Religioni U, Deptała A, Fronczak A. Assessment of pain, acceptance of illness, adjustment to life with cancer and coping strategies in prostate cancer patients. Arch Med Sci. 2016 DOI: 10.5114/ aoms.2016.58458. 